\title{
Numerical Investigation of Aerodynamic Characteristics of NACA 4312 Airfoil with Gurney Flap
}

\author{
Subah Mubassira ${ }^{*}$, Farhana Isalm Muna ${ }^{2}$, Mohammad Ilias Inam ${ }^{2}$
}

${ }^{1}$ Department of Mechanical Engineering, Bangladesh University of Engineering \& Technology, Dhaka-1000, BANGLADESH

${ }^{2}$ Department of Mechanical Engineering, Khulna University of Engineering \& Technology, Khulna-9203, BANGLADESH

Received: February 08, 2021, Revised: April 04, 2021, Accepted: April 05, 2021, Available Online: April 10, 2021

\begin{abstract}
This paper presents a two-dimensional Computational Fluid Dynamics (CFD) analysis on the effect of gurney flap on a NACA 4312 airfoil in a subsonic flow. These numerical simulations were conducted for flap heights $1.5 \%, 1.75 \%, 2 \%$ and $3 \%$ of chord length at fixed Reynold Number, $\operatorname{Re}\left(5 \times 10^{5}\right)$ for different angle of attack $\left(0^{\circ} \sim 16^{\circ}\right)$. ANSYS Fluent commercial software was used to conduct these simulations. The flow was considered as incompressible and K-omega Shear Stress Transport (SST) model was selected. The numerical results demonstrate that lift coefficient increase up to around 120 AoA (angle of attack) for NACA 4312 with and without gurney flap. For every AoA lift coefficient and drag coefficient presented proportionate behavior with flap height. However, lift coefficient was decreased after around $12^{\circ}$ angle of attack due to flow separation. Maximum lift to drag ratio was found at around $4^{\circ}$ AoA for every flap length and airfoil with flap of $1.5 \% \mathrm{C}$ (chord length) had shown the most optimized aerodynamic performance through the analysis. This study concluded that airfoil with gurney flap displayed enhanced aerodynamic performance than the airfoil without gurney flap due to the delay in flow separation.
\end{abstract}

Keywords: CFD, Airfoil, Gurney flap, Lift-Coefficient, Drag-Coefficient, Pressure-Coefficient.

This work is licensed under a Creative Commons Attribution-Non Commercial 4.0 International License.

\section{Introduction}

Airfoil design is important for the wing and control surface performance in aerospace engineering. CFD investigation is faster and cheaper than experimental testing. An airfoil is the cross-sectional shape of a wing [1]. Gurney flap or wicker bill is a lift enhancing device which is vastly used in aerodynamics. Gurney flap is a micro tab attached at trailing edge on airfoil's lower surface side perpendicularly. Attaching a gurney flap with an airfoil is easy method to increment the lift co-efficient of the airfoil mechanically. For increased lift generation takeoff can be steeper, resulting reduced noise. Also for better lift to drag ratio, the aircraft can achieve cruise altitude quicker. It also increases fuel-efficiency [2]. By attaching the boundary layer up to trailing edge gurney flap increases the lift co-efficient [3]. Common applications of gurney flap are in auto racing, helicopter horizontal stabilizers and high lift aircraft like banner-towing airplanes. Liebeck [4] first experimented on gurney flap to investigate the aerodynamic characteristics in wind tunnel. He observed that there was a lift enhancement at every angle of attack with respect to clean airfoil. Neuhart and Pendergraft [5] examined NACA 0012 wing with various gurney flap in a water tunnel study and justified Lieback's statement. Jeffrey mentioned that gurney flaps were initially used for improving downforce and stability in racing cars by the race car driver Daniel Gurney [6]. Jang [2] investigated the lift enhancement of gurney flap in his experiment. Yoo [7] observed the increase of lift co-efficient through his experiment. Li [8] verified this fact by his observation too. A formation of a small recirculation region at upstream of the flap were observed by all of them. Fernandez-Gamiz [9] analyzed the outcome of Vortex Generators and Gurney Flaps on a wind turbine. Armendenia [10] observed the improvement of a modification method for the gurney flap height for different wind and rotor blade airfoil geometry setups and concluded the non-linear dependency of lift to drag ratio on AoA and GF height. Graham [11] experimented the consequence of width and height of GF by using open circuit subsonic wind tunnel. A proportional relation between lift and flap height and an inversely proportional relation between lift and flap thickness were established in his study. A CFD analysis was done by Jain [12] to examine the impact of gurney flap on NACA 0012 airfoil for various heights at varying locations from trailing edge. It was observed that 0.015 height to chord ratio $(\mathrm{H} / \mathrm{C})$ of gurney flap resulted maximum lift coefficient $\left(\mathrm{C}_{\mathrm{l}}\right)$. Storms [13] experimentally measured aerodynamic properties for NACA 4412 airfoil with GF and vortex generator and suggested that by using both GF and Vortex generator simultaneously, airfoil displayed better performance than using these individually. Ankit kumar [1] analyzed numerically the ground effect on NACA 4412 airfoil with varying AoA and gurney flap ranging from $0.5 \% \mathrm{C}$ to $2.5 \% \mathrm{C}$. Airfoil with $1.5 \% \mathrm{C}$ flap had shown the maximum lift to drag ratio in the study. A significant enhancement in performance was observed by Myose [14] during the investigation of the gurney flap effect on NACA0011 and GS(W)-2 airfoils. Cole [15] inspected the aerodynamic impact of gurney flap at varying height in subsonic, low-turbulence wind tunnel and chord-wise locations of various airfoils. He proposed that GF at trailing edge showed better result and witnessed lift enhancement for each airfoils. Ahmed [16] experimented the flow behavior of NACA 4412 airfoil with little turbulence and moving ground simulation at Reynolds no. $3 \times 10^{5}$ with varying AoA and obtained that the airfoil geometry also had a great impact on aerodynamic performance aside from AoA and ground clearance. Webb [17] did a wind tunnel test for both wing and airfoil section with varying lengths of GF and perceived a greater lift to drag ratio. Camocardi [18] experimented in wind 
tunnel on an airfoil with flexible GF. The performance of fixed gurney flap joint with airfoil showed higher lift coefficient than the movable gurney flap. $30 \%$ enhancement in lift coefficient was seen by Maughmer [19] during the inspection of the aerodynamics properties of gurney flaps in subsonic wind tunnels at Reynolds number $10^{6}$. Chand [20] compared the aerodynamics properties of a multi element airfoil and a standard NACA airfoil where the performance was found superior for multi element airfoil.

Analyzing the aforementioned literature, it is quite apparent that enough light hasn't been shed on enhancing the performance of NACA 4312 airfoil. The aim of this present study is to investigate the effect of GF height on aerodynamic performance and evaluating the optimum height for the airfoil. The flow characteristics were compared between airfoil with and without flap computationally for Reynolds number $5 \times 10^{5}$ with varying AoA $\left(0^{\circ}-16^{\circ}\right)$. Since the geometry of airfoil has a great impact on aerodynamic characteristics, it is essential to determine the height of the GF. Finite volume method (FVM) was used to carry out to solve the cases on ANSYS Fluent and $k-\omega$ SST was chosen as a turbulence model for this study.

\section{Computational Method}

\subsection{Geometry Modeling}

NACA 4312 airfoil was chosen as geometrical model for gurney flap study. The NACA-4312 airfoil indicates maximum camber of $4 \% \mathrm{C}$ which is situated at $30 \% \mathrm{C}$ from the leading edge. Maximum thickness of the airfoil is $12 \%$ length of chord. For present analysis, chord length was taken $1000 \mathrm{~mm}$. Airfoil geometry was generated in SolidWorks by importing coordinates file and is shown in Fig. 1(a) and in Fig. 1(b) airfoil with flap is shown. Reviewing previous literatures, four different lengths of $\mathrm{GF}$ were chosen for this study which were of $1.5 \% \mathrm{C}, 1.75 \% \mathrm{C}$, $2 \% \mathrm{C}$ and $3 \% \mathrm{C}$ with varying $\mathrm{AoA}\left(0^{\circ}-16^{\circ}\right)$.

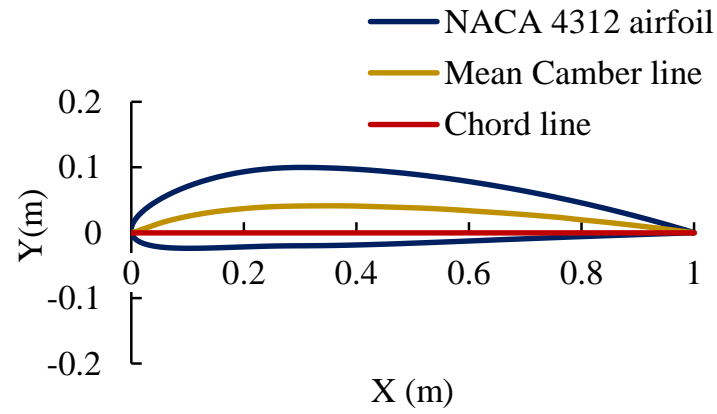

(a)

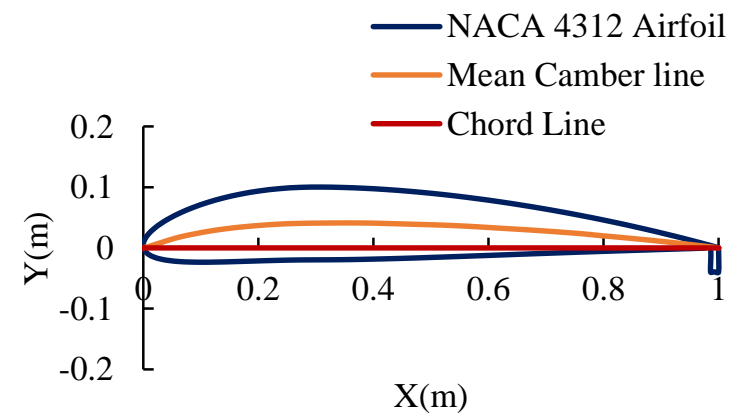

(b)

Fig. 1 (a) NACA 4312 airfoil; (b) NACA 4312 with flap.

\subsection{Governing Equations}

Several types of turbulence models are generally used to solve according to the type of flow like $k-\omega$ SST and $k-\epsilon$ etc. $k-\epsilon$ is more suitable for flow away from the wall, while $k-\omega$ SST model is best suited for near the wall flow region, where adverse pressure gradient is developed. $k-\omega$ SST model shows better numerical analysis and results than $k-\epsilon$ model [21].

$k-\omega$ SST model is a two equation eddy viscosity model which is constructed upon conservation of mass, momentum and energy accompanied by two additional transport equations to characterize the turbulent properties model. It is a hybrid model combining the Wilcox $k-\omega$ and the $k-\epsilon$ models.

The continuity model:

$\frac{\partial}{\partial x_{i}}\left(\rho u_{i}\right)=0$

The momentum model:

$$
\begin{aligned}
& \frac{\partial}{\partial x_{j}}\left(\rho u_{i} u_{j}\right)=\frac{\partial p}{\partial x_{i}} \\
&+\frac{\partial}{\partial x_{j}}\left[\mu\left(\frac{\partial u_{i}}{\partial x_{j}}+\frac{\partial u_{j}}{\partial x_{i}}-\frac{2}{3} \delta_{i j} \frac{\partial u_{l}}{\partial x_{l}}\right)\right] \\
&+\frac{\partial}{\partial x_{j}}\left(-\rho \overline{u_{\imath}^{\prime} u_{\jmath}^{\prime}}\right)
\end{aligned}
$$

Here in Equations (1) and (2), $\rho$ denotes density, $\mu$ denotes dynamic viscosity and $u$ denotes inlet velocity of the fluid.

The turbulent kinetic energy and dissipation rate of eddy viscosity are represented by $\mathrm{k}$ and $\omega$ respectively. These are gained from Equations (3) and (4):

$$
\begin{aligned}
\frac{\partial}{\partial t}(\rho k)+\frac{\partial}{\partial x_{i}}(\rho k & \left.u_{i}\right) \\
& =\frac{\partial}{\partial x_{j}}\left(\Gamma_{k} \frac{\partial k}{\partial x_{j}}\right)+\tilde{G}_{k}-Y_{k}+S_{k}
\end{aligned}
$$

and

$$
\begin{aligned}
\frac{\partial}{\partial t}(\rho \omega)+\frac{\partial}{\partial x_{i}}\left(\rho \omega u_{i}\right) & \\
& =\frac{\partial}{\partial x_{j}}\left(\Gamma_{\omega} \frac{\partial \omega}{\partial x_{j}}\right)+G_{\omega}-Y_{\omega}+D_{\omega} \\
& +S_{\omega}
\end{aligned}
$$

In these equations, $\tilde{G}_{k}$ represents the generation of turbulence kinetic energy due to mean velocity gradients. $G_{\omega}$ represents the generation of $\omega . \Gamma_{k}$ and $\Gamma_{\omega}$ represent the effective diffusivity of $k$ and $\omega$. $Y_{\omega}$ and $Y_{k}$ represent the dissipation of $k$ and $\omega$ due to turbulence. $D_{\omega}$ represents the cross-diffusion term, calculated as described below $S_{\omega}$ and $S_{k}$ are user-defined source terms. As the flow was considered to be incompressible, the energy equation was not required for the present study.

\subsection{Boundary Condition with Domain}

The domain was designed with a semicircle and rectangle. The upstream, upper and lower domain were $12.5 \mathrm{C}$ away and the downstream was $20 \mathrm{C}$ away ( $\mathrm{C}$ is referred as chord length) to reduce the boundary effect.

Fig. 2 shows the domain taken for the airfoil. Based on geometry $\mathrm{ABCDE}, \mathrm{BCD}$ was set as constant velocity inlet and 
$\mathrm{AE}$ as a pressure outlet. The airfoil wall as well as flap were assumed with no slip boundary condition. The Reynolds No was fixed at $5 \times 10^{5}$, the inlet velocity is assumed $7.5 \mathrm{~m} / \mathrm{s}$ which directed to a Mach number less than 0.3. For this low Mach number, the flow was deliberated to be incompressible. With different angle of attack, the components of velocity was measured using $u \sin \alpha$ and $u \cos \alpha$ (where $\mathrm{u}$ is the free stream velocity of the flow and $\alpha$ is the corresponding AoA). Air was assumed as an ideal fluid with a constant density of $1.225 \mathrm{~kg} / \mathrm{m}^{3}$ and dynamic viscosity of $1.7894 \times 10^{-5} \mathrm{~kg} / \mathrm{m}-\mathrm{s}$.

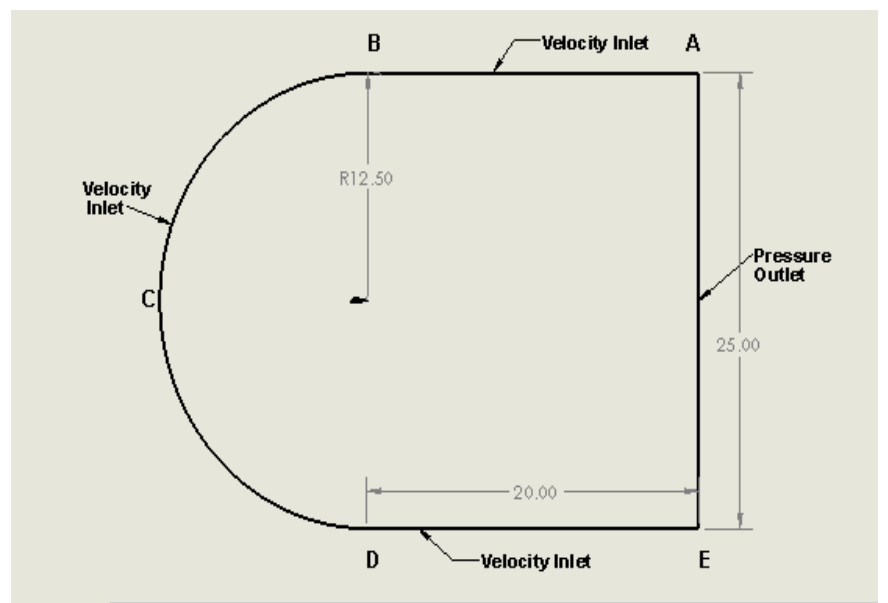

Fig. 2 Computational Domain with Boundary condition

\subsection{Numerical Setup}

In FLUENT, the governing equations were discretized using a second-order upwind scheme and the solver of these equations was run on pressure based Coupled algorithm. This method obtained a greater performance compared to segregated solution schemes [22]. Instead of rotating the airfoil, the flow direction of air was inclined along the increasing angle of attack. The convergence criterion was set as 1e-07 and double precision was fixed for accuracy. The steady-state Reynolds Average NavierStokes (RANS) equation was deciphered using the Least squares cell based gradient option and pressure-based solver was chosen.

\subsection{Mesh Generation}

Mesh generation is very important aspect for CFD simulation. Mesh or grid is used for better convergence properties. The element and nodal data achieved from this discretization is beneficial for the numerical results of Finite Element Method (FEM) and for the aerodynamic investigation. As the geometry was complicated unstructured mesh was selected for grid generation which had been done in ANSYS Meshing. Fig. 3 presents an augmented view of the mesh structure of without flap and 3\% flap. In Fig. 3(a) finer mesh is apparent close to the surface of the airfoil and trailing edge, and in Fig. 3(b) around the flap by introducing inflation layer to achieve suitable resolution of the boundary layer and the area around the Gurney flap. For inflation, 16 layers were considered for a good mesh and maximum thickness of Inflation had been used $0.007 \mathrm{~m}$. Higher mesh resolution had been used near leading edge and trailing edge. By changing the edge sizing and body sizing, element numbers and node numbers had been varied to find proper mesh for accurate result.

The non-dimensional wall parameter is defined as:
$Y^{+}=y \times \frac{\sqrt{\left(\tau_{w}\right) / \rho}}{\mu}$

where, $y$ is the distance from the wall to the centroid of the wall adjacent first cell and $\tau_{w}$ is the wall shear stress. From reference [22] to acquire accurate simulation result, $Y^{+} \sim 1$ was recommended which denotes finer mesh in the near wall region. For each simulation of airfoil with and without flap the anticipated $Y^{+}$value was detected.

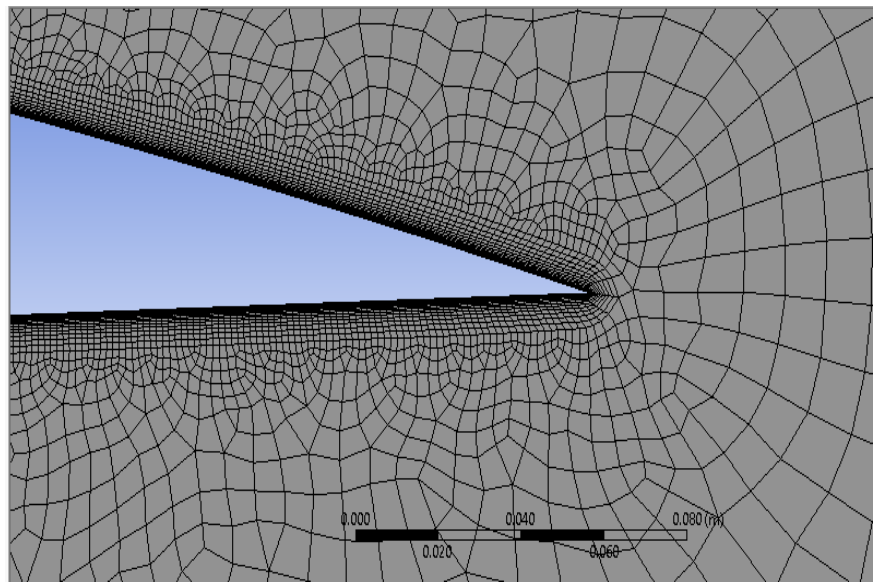

(a)

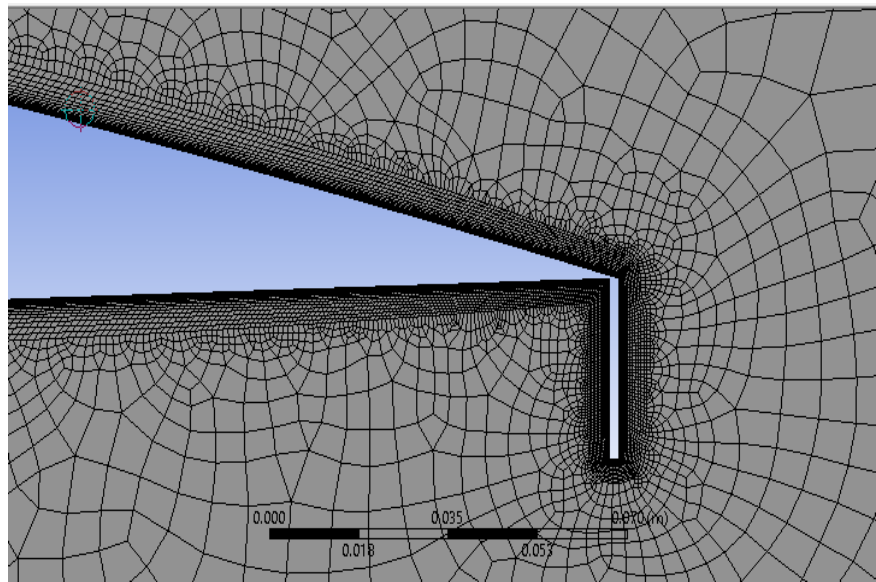

(b)

Fig. 3 Mesh Generated around (a) without flap (b) with 3\% flap

\subsection{Mesh Independence Test}

Mesh independence test were performed to evaluate the most optimized mesh to obtain a precise numerical result. For this study a set of simulations were conducted to get the optimized mesh. The refinement had been achieved by altering the body sizing and edge sizing for each mesh. Fig. 4(a) shows the effect of mesh elements on the lift coefficient of NACA-4312 airfoil without flap at angle of attack $0^{\circ}$. Results demonstrate that mesh with elements number higher than 120055 could produce a mesh independent result. Fig. 4(b) demonstrates the effect of mesh element number on the lift coefficient of NACA-4312 with $1.5 \% \mathrm{C}$ flap and AoA is $0^{\circ}$. It is evident from the graph that mesh with elements number higher than 108000 the lift coefficient becomes constant. So, the mesh with 108000 elements was considered for the numerical simulation of NACA-4312 airfoil with flap. 


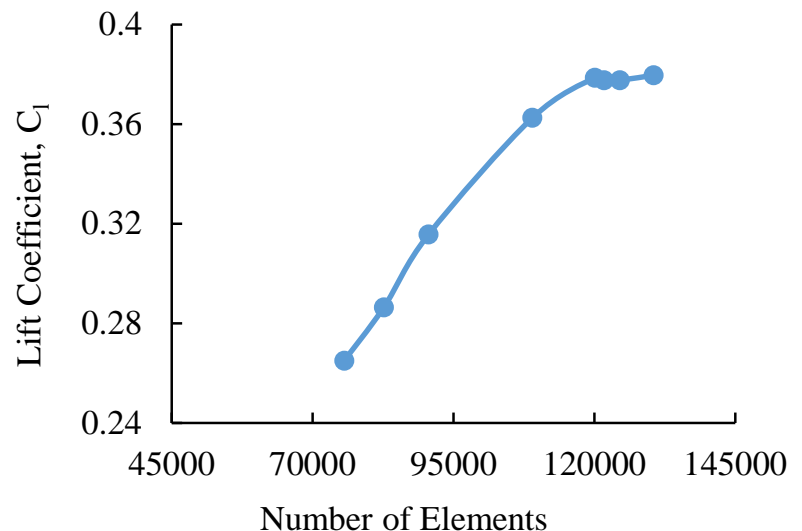

(a)

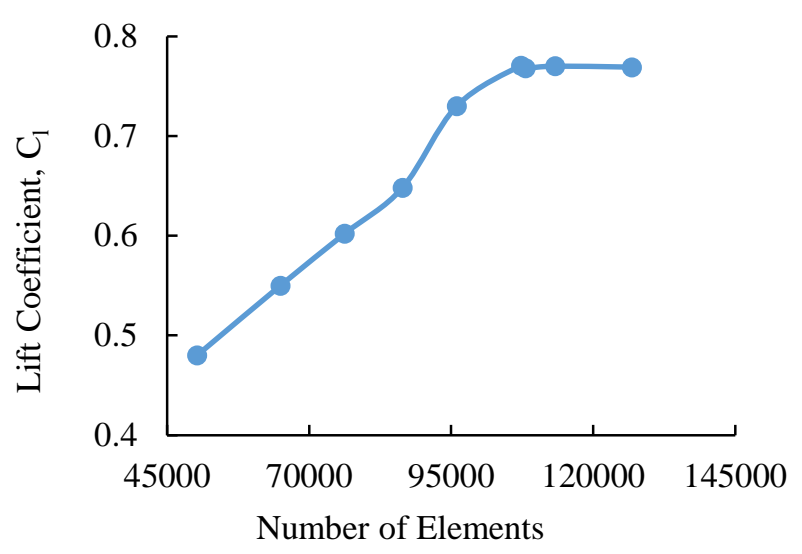

(b)

Fig. 4 Variation of Lift coefficient with Number of elements (a) without flap at $0^{\circ} \mathrm{AoA}(\mathrm{b})$ with $1.5 \%$ flap, $0^{\circ} \mathrm{AoA}$

\section{Results and Discussion}

Fig. 5(a) depicts the relation between lift coefficient and AoA for different flap height. It had been observed from the figure that the lift coefficient, $\mathrm{C}_{\mathrm{l}}$, increases up to $10^{\circ}-12^{\circ}$ and then starts to fall due to flow separation which is caused by adverse pressure gradient at the trailing edge. This phenomenon is known as stall. It was also observed that airfoil with gurney flap showed a significant jump on lift coefficient at all corresponding angle of attack. Higher flap height have higher lift coefficient. In this graph it is perceived that $3 \% \mathrm{C}$ flap produced the highest lift coefficient and the lowest lift coefficient is produced by the airfoil without flap.

Fig. 5(b) shows the relation between drag coefficient and angle of attack. It was perceived from the graph that drag increased very slowly at lower angle of attack however behind the stall angle due to the flow separation drag increased suddenly. Results also demonstrated that drag coefficient increases with increasing lengths of gurney flap. The airfoil with 3\%C flap showed the sharpest increase of drag around stall.

As the lift and drag both increase along with the increasing AoA, it is more efficient to calculate the $C_{l} / C_{d}$ value and it was depicted in Fig. 5(c). Initially the graph showed a positive slope but after reaching a maximum value it dropped which signified that the rate of increasing lift is slower than the rate of increasing drag causing a major drawback in airfoil efficiency. The airfoil with $1.5 \% \mathrm{C}$ flap showed the most efficient result while flap with $3 \% \mathrm{C}$ showed drastic case of drag increment.

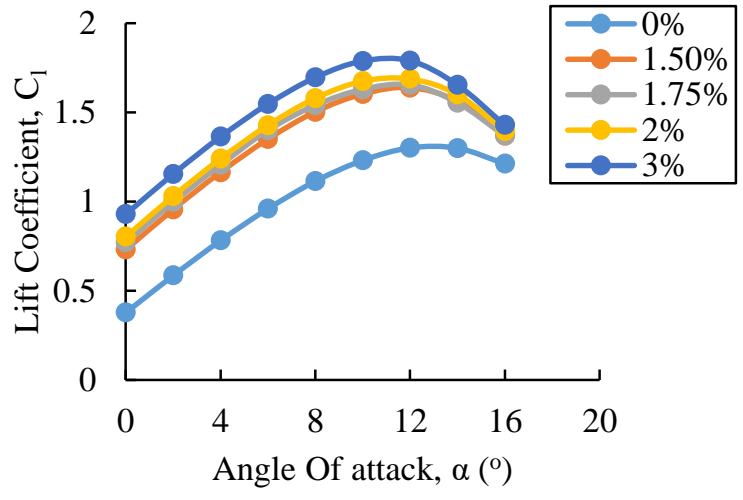

(a)

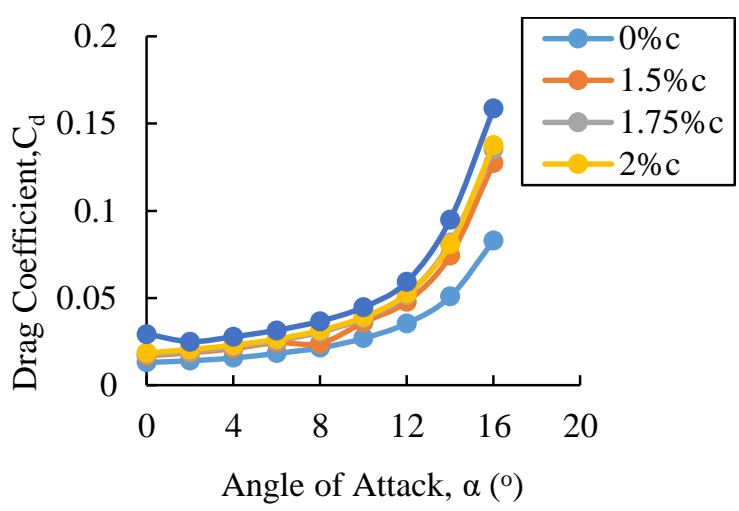

(b)

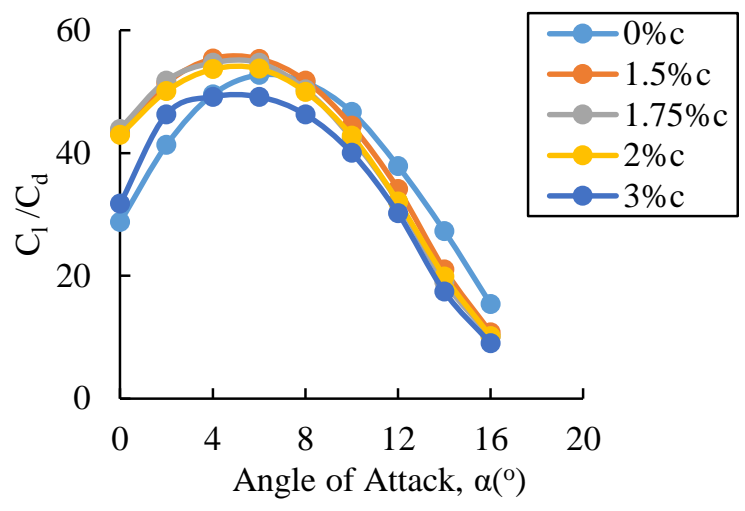

(c)

Fig. 5 Relation between (a) Lift Coefficient vs Angle of Attack; (b) Drag Coefficient vs Angle of Attack; and (c) $C_{1} / C_{d}$ vs Angle of Attack for various length of flap

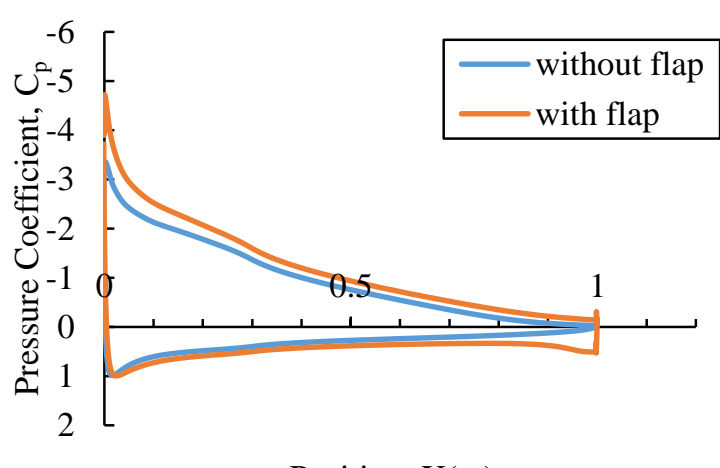

Position, $\mathrm{X}(\mathrm{m})$

Fig. 6 Variation of Pressure Coefficient with positon on airfoil surface for without flap and with flap at $10^{\circ}$ AoA 


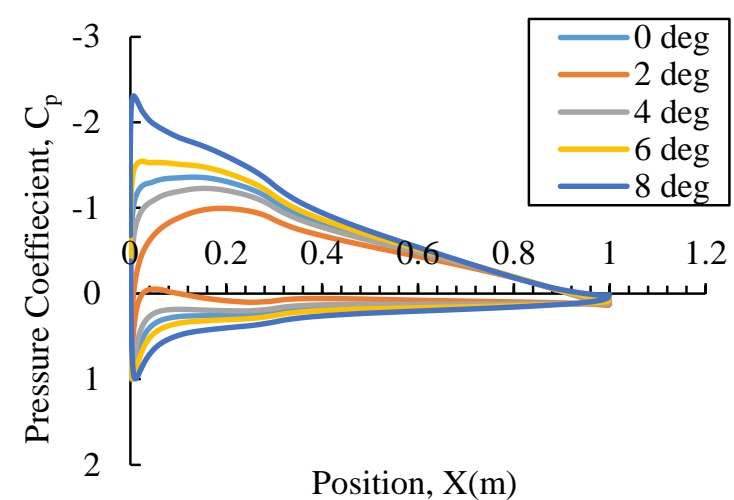

(a)

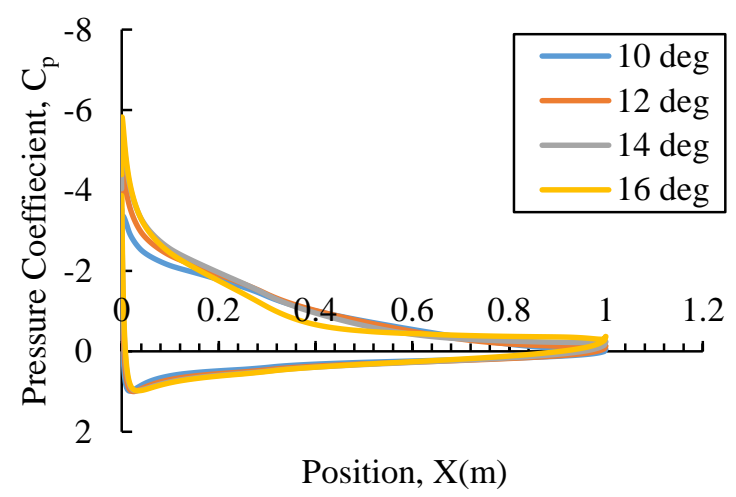

(b)

Fig. 7 Variation of Pressure Coefficient with positon on airfoil surface for without flap at different AoA

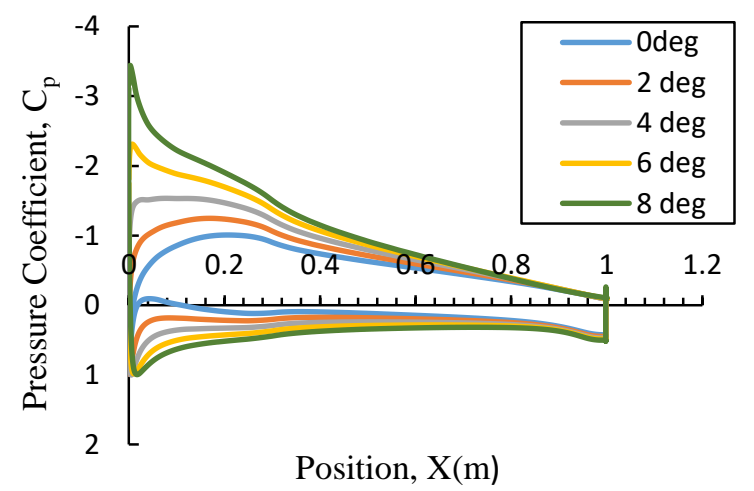

(a)

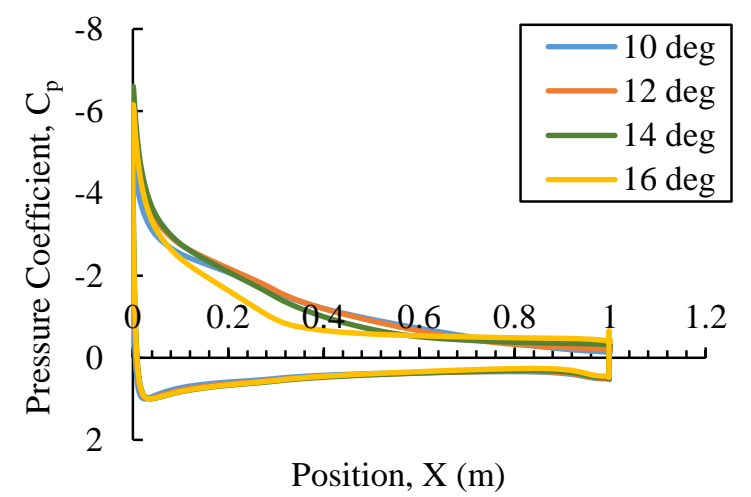

(b)

Fig. 8 Variation of Pressure Coefficient with positon on airfoil surface for with $1.5 \% \mathrm{C}$ flap at different AoA
Fig. 6 displays the relation between pressure coefficient and the position along the chords for airfoil without flap and with $1.5 \% \mathrm{c}$ flap at $10^{\circ} \mathrm{AoA}$. The high pressure coefficient had been observed for the lower surface of the airfoil and the lower pressure coefficient surface denoting the upper surface of the airfoil. Because of this pressure difference the airfoil can generate lift. The pressure alteration between upper and lower surface rose largely in the trailing edge section of the airfoil due to the flap. From Fig. 6 it has been seen that for airfoil without flap at $\alpha=10^{\circ}$ the flow separation occurs in $86 \% \mathrm{C}$. For same angle of attack, flow separation took place at $92 \% \mathrm{C}$ when the gurney flap is attached with the airfoil. From Fig. 6 it can be seen that the difference of pressure co-efficient between upper and lower surface is greater for the airfoil with gurney flap than the clean airfoil. As the flow separation occurred late in the gurney flap case, the lift increment occurred in airfoil with gurney flap.

As is depicted in Fig. 7(a), at $\alpha=0^{\circ}, 13.2 \% \mathrm{C}$ of the upper surface from leading edge has undergone favorable pressure gradient. After that, the air moves fluently over the upper surface without being separated. With increasing AoA, the leading edge suction is enhanced, but the favorable pressure gradient is decreased for $\alpha=4^{\circ}$. In Fig. 7(a), the leading edge suction was enhanced again, and the suction side of the airfoil had undergone adverse pressure gradient after $0.7 \% \mathrm{C}$ of the upper surface at $\alpha=8^{\circ}$. As a result, flow started to separate at $91 \% \mathrm{C}$. In the separation zone, the pressure remained constant. From Fig. 8(b), the separation point for $\alpha=12^{\circ}$ occurred in $75 \% \mathrm{C}$ in clean airfoil. But from Fig. 8(b), for same angle of attack the separation delayed to $78 \% \mathrm{C}$ in airfoil with gurney flap. $\alpha=12^{\circ}$ is the stall angles for the airfoil with $1.5 \% \mathrm{C}$ gurney flap and clean airfoil respectively. As after stall angles, lift decreased and the drag increased, the separation point for airfoil with gurney flap had been seen at $53 \% \mathrm{C}$ for $\alpha=14^{\circ}$ from Fig. 8(b) where the separation point for clean airfoil had been seen at $60 \% \mathrm{C}$ for same angle of attack from Fig. 7(b). Flow separation is occurred in the pressure side of the airfoil close to the trailing edge and before the GF creating a huge recirculation region, causing an increment in pressure. Pressure co-efficient is observed maximum for all simulations at leading edge stagnation point as the local velocity becomes zero there. When AoA increased, the stagnation point shifted behind along the lower surface causing a nose-up pitching moment. Highest pressure co-efficient had been perceived in lower surface graph. Fig. 9 depicts the flow separation point is delayed for airfoil with flap up to stall angle.

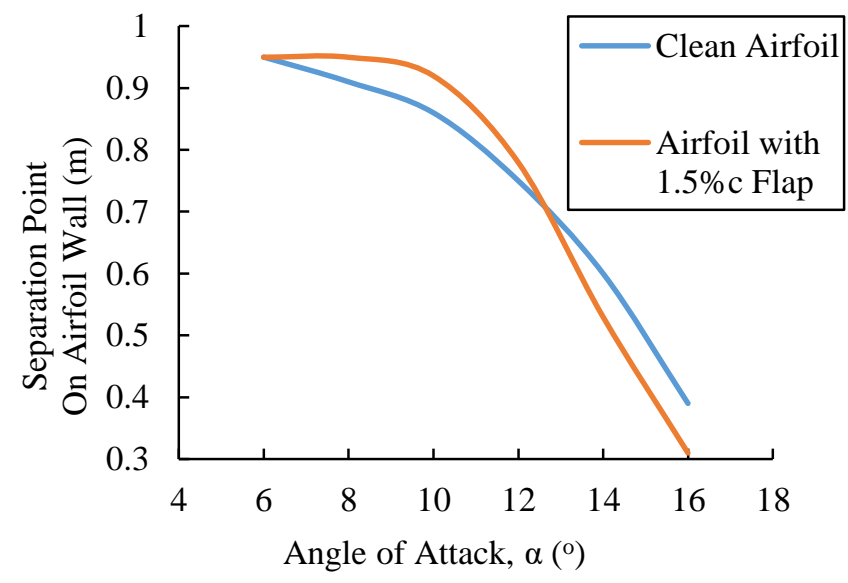

Fig. 9 Separation Point on airfoil wall for different AoA for clean and with $1.5 \% \mathrm{C}$ flap airfoil 
Fig. 10 presents the pressure distribution on the airfoil with various height of gurney flap at $10^{\circ} \mathrm{AoA}$. The Kutta condition at the trailing edge is changed by deploying a GF which leads to a pressure increment for both the upper and lower airfoil surface. As there is a pressure difference between upper and lower surface, the load capacity of the airfoil rises resulting increment in lift. With increasing height of gurney flap the lift coefficient also increases.

From Fig. 11 it is quite evident that the upper surface of the airfoil had lesser pressure than the lower surface. At moderate AoA, the pressure on both surfaces were increased and thus the lift as well as drag also increased, which then bring about the decreasing nature of lift to drag ratio. Also, from the pressure contour it is observed that the front side of the GF had positive pressure and the rear side had negative pressure, resulting the increment of drag of the airfoil.

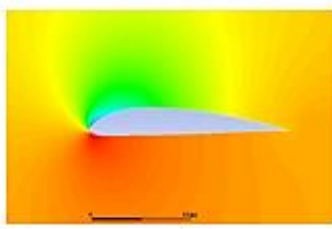

(a) Without $10^{\circ}$

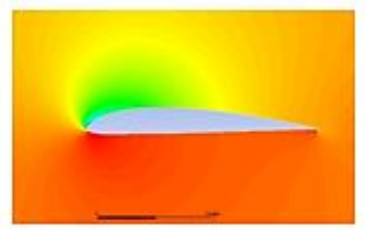

(b) $1.5 \% \mathrm{c} 10^{\circ}$

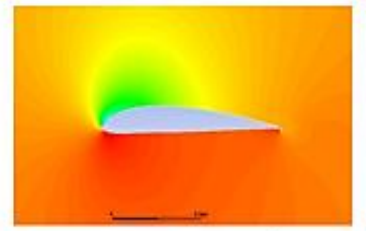

(c) $1.75 \% \mathrm{c} 10^{\circ}$

\subsection{Trailing Edge Flow Structure}

In Fig. 12(a) flow behavior of airfoil without flap with AoA of $4^{\circ}$ is shown and Fig. 12(b) depicts the flow behavior of airfoil with flap $1.5 \%$ with angle of attack $4^{\circ}$. At this angle of attack, the flow created two vortices, one is at the downstream of the flap and the other one is at the upstream creating the separation bubble. At lower angle of attack, one very strong anti-clockwise vortex is created down the stream of the GF and no contra rotating distinct vortices was seen. This vortex induces the wake region to proceed downstream which results in delaying the flow separation and the reduction of pressure due to the vortices results in increasing the suction. At the lower surface upstream of the flap velocity is decreased which causes in pressure increase and this adds to the rise of the suction in the downstream resulting the increment of lift.

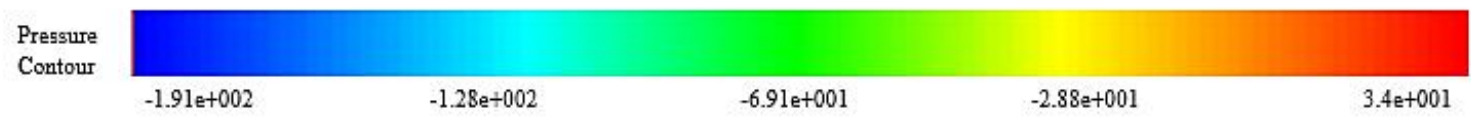

Fig. 10 Pressure contour of airfoil with different height of flap at $10^{\circ}$ angle of attack

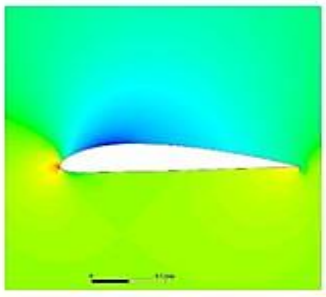

(a) $0^{\circ}$

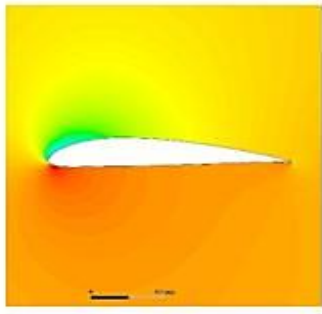

(f) $10^{\circ}$

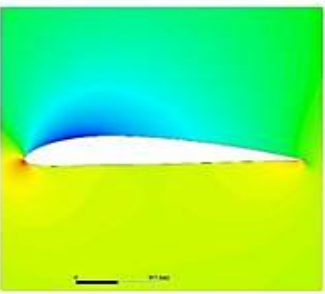

(b) $2^{\circ}$

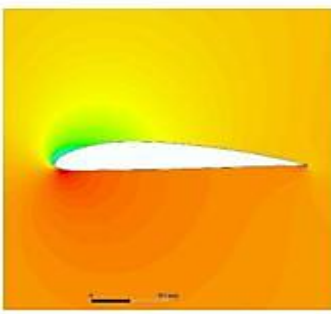

(g) $12^{\circ}$

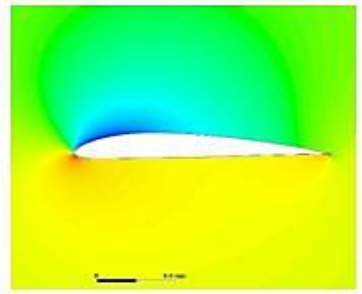

(c) $4^{\circ}$

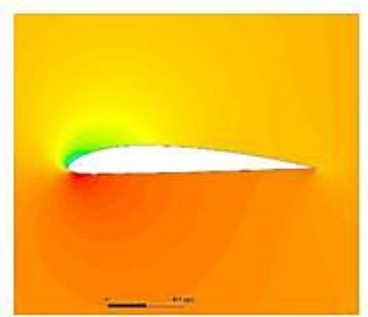

(h) $14^{\circ}$

Pressure Contour

$-4 e-01 \quad-4 e-01 \quad-3 e-01 \quad-2 e-01 \quad-1 e-01 \quad-4 e+00 \quad 3 e+00 \quad 1 e+01 \quad 2 e+01 \quad 3 e+01 \quad 3 e+01$

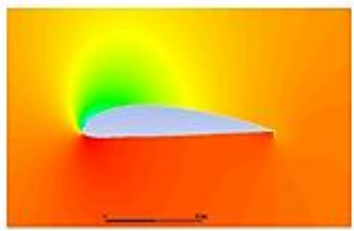

(d) $2 \%$ c $10^{\circ}$

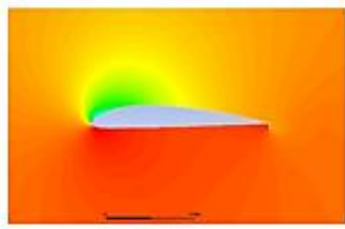

(e) $3 \% \mathrm{c} 10^{\circ}$

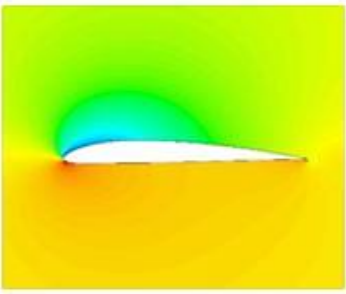

(d) $6^{\circ}$

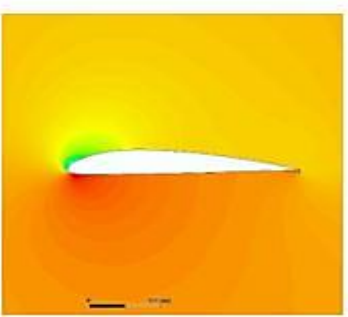

(i) $16^{\circ}$

Fig. 11 Pressure contour of airfoil with 1.5\%C flap at different angle of attack 


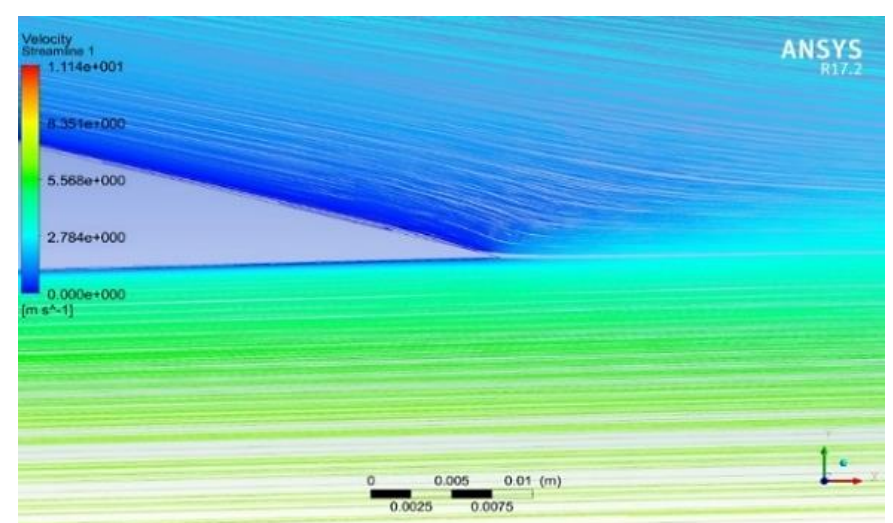

(a)

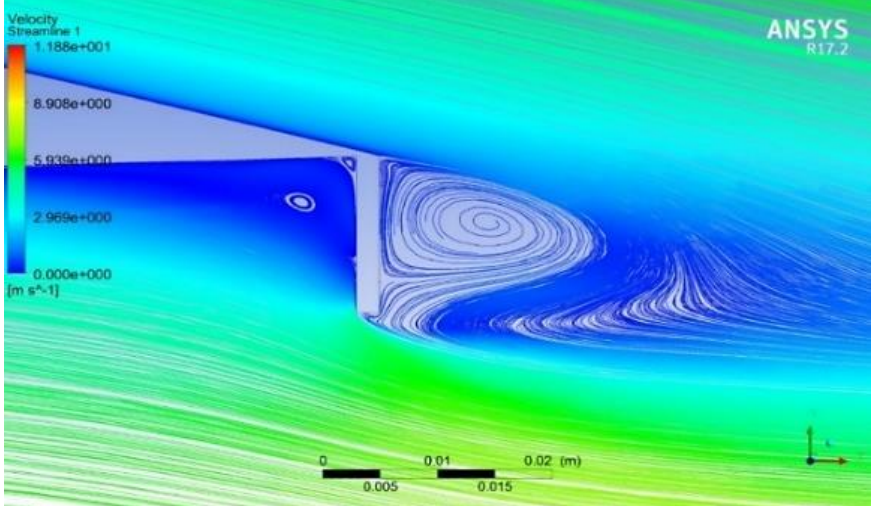

(b)

Fig. 12 Flow behavior of (a) without flap and (b) with flap at AoA $4^{\circ}$ at the trailing edge

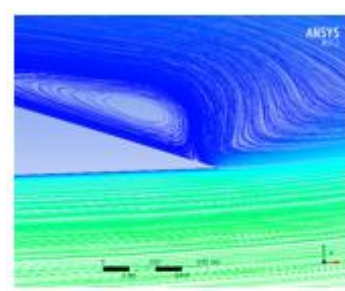

(a) Without $10^{\circ}$

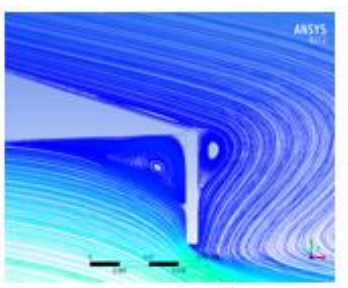

(b) $1.5 \% \mathrm{c} 10^{\mathrm{D}}$

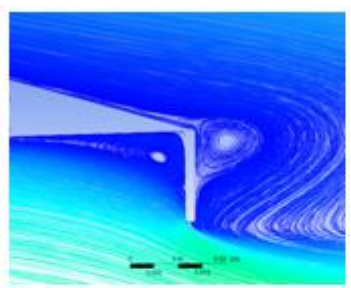

(c) $1.75 \% 10^{\circ}$

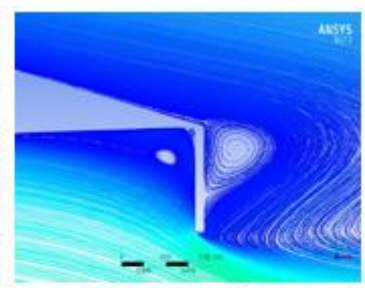

(d) $2 \%$ c $10^{\circ}$

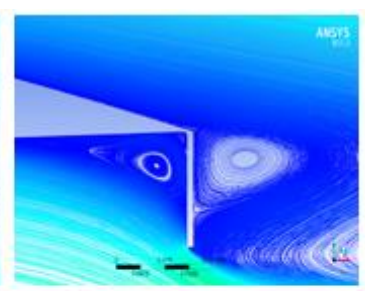

(d) $3 \%<10^{\circ}$

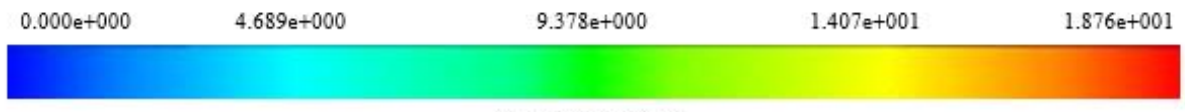

Velocity Streamline

Fig. 13 Velocity Streamlines of airfoils with 1.5\%C flap (left column) and without flap (right column)

(a) $0^{\circ}$

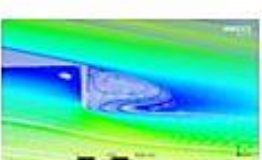

$-$

(b) $2^{o}$

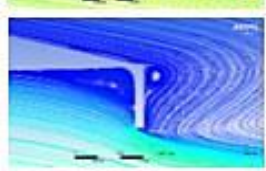

$-$

(c) $4^{\circ}$

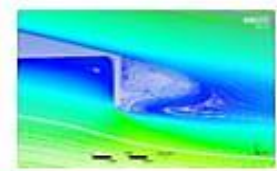

(d) $6^{\circ}$

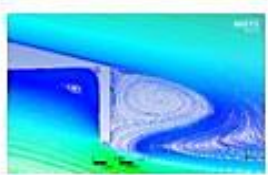

(e) $8^{\circ}$

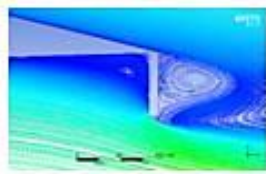

Without flap
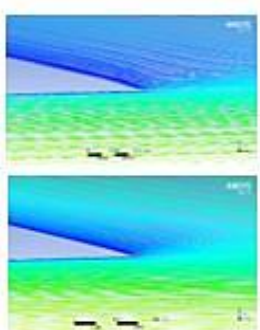

$--$

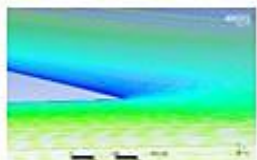

$-\cdots$

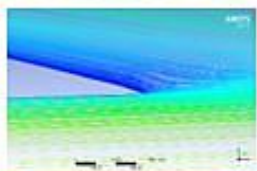

$-\cdots$

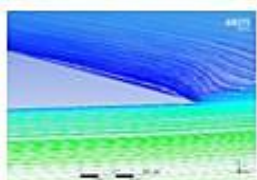

With flap

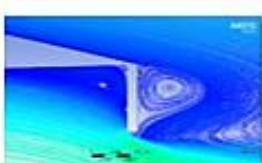

(g) $12^{\circ}$

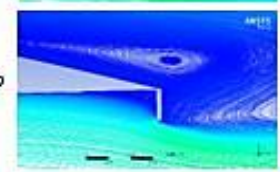

(h) $14^{\circ}$

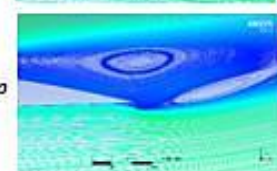

(i) $16^{\circ}$

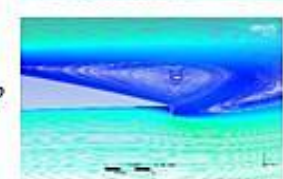

\section{Without flap}
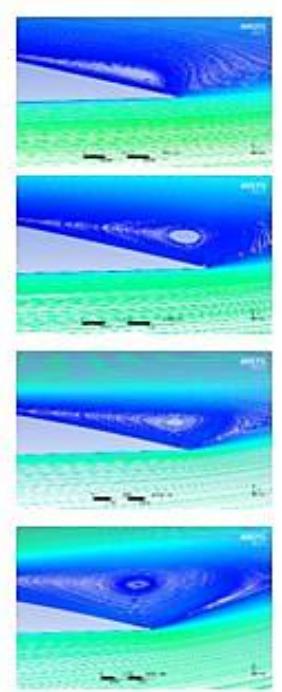

$0.00 \mathrm{e}+00$

4. $777 \mathrm{e}+00$

$9.554 \mathrm{e}+00$

$1.433 \mathrm{e}+01$

$1.91 \mathrm{e}+01$

Velocity

Streamline

Fig. 14 Velocity Streamlines of airfoils with flap of different heights and without flap

In Fig. 13 it had been depicted the differences of flow behavior between an airfoil with flap and without flap with increasing angle of attack. Fig. 13 shows that the air moves fluently without separation for clean airfoil at $\alpha=4^{\circ}$. In downstream of the leeward of the GF, there is a wake region with two vortices. Since GF has effects as a point vortex, it enlarges the circulation of the airfoil. However, when a GF had been installed, the flow separation on the upper surface is reduced so 
that the suction is greater and vortex creation behind the flap which results the delay of flow separation. At higher AoA (for airfoil with flap) these vortices move to the upper surface of the airfoil enhancing the lift to drag ratio which is quite equal as the airfoil without flaps. From Fig. 14 flow structure had been showed for different height of the gurney flap at angle of attack $10^{\circ}$. It clearly shows that the flow separation is occurring lately. With the increasing height the vortex after the gurney flap is getting bigger and clear.

\section{Conclusion}

A CFD analysis of a NACA 4312 airfoil with a Gurney flap has been done precisely. The two-dimensional flow was measured using ANSYS Fluent with the two-equation turbulence model of K-omega SST. The main intention of using the gurney flap is lift increment. Gurney flap can produce the same lift with lesser AoA. In comparison with a clean airfoil, lift coefficient and lift to drag ratio were enhanced by the Gurney flaps. By deploying gurney flap at trailing edge, flow can be optimized for anticipated flow behavior. So gurney flap can be used as liftenhancement device. Along with the increment of the height of the flap, lift as well as drag increases but the aerodynamics performance is not always up to the mark. It was inspected that the relation between Lift/drag ratio and gurney flap length is nonlinear and it relied on the angle of attack. The maximum value of $\mathrm{Lift} / \mathrm{drag}$ ratio is attained with Gurney flap of $1.5 \% \mathrm{C}$ which is considered as the best performance for this study. The contours of static pressure, velocity and the coefficient of lift, coefficient of drag distribution and coefficient of pressure is calculated. Outcomes from this research can be utilized as a path for achieving higher lift on aircraft by using GF.

\section{References}

[1] Kumar, A., Chaubdar, P., Sinha, G.S. and Harichandan, A.B., 2021. Performance Analysis of NACA4412 Airfoil with Gurney Flap. In Proceedings of International Conference on Thermofluids (pp. 167-176). Springer, Singapore.

[2] Jang, C.S., Ross, J.C. and Cummings, R.M., 1998. Numerical investigation of an airfoil with a Gurney flap. Aircraft Design, 1(2), pp.75-88.

[3] Fatahian, H., Salarian, H., Nimvari, M.E. and Khaleghinia, J., 2020. Effect of Gurney flap on flow separation and aerodynamic performance of an airfoil under rain and icing conditions. Acta Mechanica Sinica, pp.1-19.

[4] Liebeck, R.H., 1978. Design of subsonic airfoils for high lift. Journal of Aircraft, 15(9), pp.547-561.

[5] Neuhart, D.H., 1988. A water tunnel study of Gurney flaps (Vol. 4071). National Aeronautics and Space Administration, Scientific and Technical Information Division.

[6] Zerihan, J. and Zhang, X., 2001. Aerodynamics of Gurney flaps on a wing in ground effect. AIAA Journal, 39(5), pp.772-780.

[7] Yoo, N.S., 2000. Effect of the Gurney flap on a NACA 23012 airfoil. KSME International Journal, 14(9), pp.1013-1019.
[8] Li, Y., Wang, J. and Zhang, P., 2002. Effects of Gurney flaps on a NACA0012 airfoil. Flow, Turbulence and Combustion, 68(1), pp.27-39.

[9] Fernandez-Gamiz, U., Zulueta, E., Boyano, A., Ansoategui, I. and Uriarte, I., 2017. Five megawatt wind turbine power output improvements by passive flow control devices. Energies, 10(6), p.742.

[10] Aramendia, I., Saenz-Aguirre, A., Fernandez-Gamiz, U., Zulueta, E., Lopez-Guede, J.M., Boyano, A. and Sancho, J., 2018. Gurney Flap Implementation on a DU91W250 Airfoil. In Multidisciplinary Digital Publishing Institute Proceedings (Vol. 2, No. 23, p. 1448).

[11] Graham, M., Muradian, A. and Traub, L.W., 2018. Experimental study on the effect of Gurney flap thickness on airfoil performance. Journal of Aircraft, 55(2), pp.897904.

[12] Jain, S., Sitaram, N. and Krishnaswamy, S., 2015. Computational investigations on the effects of Gurney flap on airfoil aerodynamics. International Scholarly Research Notices, 2015.

[13] Storms, B.L. and Jang, C.S., 1994. Lift enhancement of an airfoil using a Gurney flap and vortex generators. Journal of Aircraft, 31(3), pp.542-547.

[14] Myose, R., Papadakis, M. and Heron, I., 1998. Gurney flap experiments on airfoils, wings, and reflection plane model. Journal of Aircraft, 35(2), pp.206-211.

[15] Cole, J.A., Vieira, B.A., Coder, J.G., Premi, A. and Maughmer, M.D., 2013. Experimental investigation into the effect of Gurney flaps on various airfoils. Journal of Aircraft, 50(4), pp.1287-1294.

[16] Ahmed, M.R., Takasaki, T. and Kohama, Y., 2007. Aerodynamics of a NACA4412 airfoil in ground effect. AIAA Journal, 45(1), pp.37-47.

[17] Webb, J., Higgenbotham, H., Liebshutz, D., Potts, D., Tondreau, E. and Ashworth, J., 2001. Analysis of Gurney Flap effects on a NACA 0012 airfoil/wing section. In 19th AIAA Applied Aerodynamics Conference (p. 2483).

[18] M. E. Camocardi, J. Maranon, D. Leo, J. S. Delnero, and J. L. C. Lerner, "Gurney Flap," vol. 47, no. January, pp. 1-15, 2011.

[19] Maughmer, M.D. and Bramesfeld, G., 2008. Experimental investigation of Gurney flaps. Journal of Aircraft, 45(6), pp.2062-2067.

[20] Chand, D.V., Sriram, R. and Kumar, D.U., 2016. Aerodynamic analysis of multi element airfoil. Int J Sci Res Publ, 6(7), pp. 305-310.

[21] Pranto, M.R.I. and Inam, M.I., 2020. Numerical Analysis of the Aerodynamic Characteristics of NACA4312 Airfoil. Journal of Engineering Advancements, 1(02), pp.29-36.

[22] Fluent, A.N.S.Y.S., 2013. ANSYS fluent theory guide 15.0. ANSYS, Canonsburg, PA, 33. 